\title{
Desempenho produtivo de tambacus alimentados com dietas suplementadas com vitamina $\mathrm{E}$
}

\author{
Antônio Carlos Silveira Gonçalves ${ }^{(1)}$, Luis David Solis Murgas(1), Priscila Vieira e Rosa ${ }^{(1)}$, \\ Rodrigo Diana Navarro(2), Diego Vicente da Costa $^{(1)}$ e Edgar de Alencar Teixeira(3)
}

\begin{abstract}
(1)Universidade Federal de Lavras, Departamento de Zootecnia, Caixa Postal 37, CEP 37200-000 Lavras, MG. E-mail: antonycarl2003@yahoo.com.br, Ismurgas@dmv.ufla.br, priscila@dzo.ufla.br, diego@zootecnista.com.br (2)Universidade José do Rosário Vellano, Faculdade de Zootecnia, Rodovia MG 179, km 0, Caixa Postal 23, CEP 37130-000 Alfenas, MG. E-mail: rddnavarro@yahoo.com.br ${ }^{(3)}$ Universidade Federal de Minas Gerais, Departamento de Zootecnia, Avenida Antônio Carlos, n 6627, Bairro São Francisco, CEP 30123-970 Belo Horizonte, MG. E-mail: edgarvet@hotmail.com
\end{abstract}

Resumo - O objetivo deste trabalho foi avaliar os efeitos da suplementação da dieta de tambacus com concentrações de vitamina E sobre variáveis de desempenho e hematológicas, bem como determinar a relação da atividade da glutationa peroxidase com a inclusão de vitamina E e selênio na dieta. Foram utilizados 250 juvenis de tambacu, divididos em 25 aquários. A dieta basal constituiu-se de ração peletizada com $32 \%$ de proteína bruta e $3.300 \mathrm{kcal} \mathrm{kg}^{-1}$ de energia digestível, e inclusão de $0,40 \mathrm{mg} \mathrm{kg}^{-1} \mathrm{de}$ Se. As dietas-teste isoprotéicas e isoenergéticas - foram compostas da dieta basal com diferentes concentrações de vitamina $\mathrm{E}$ ( 0 , $\left.100,200,300,400 \mathrm{mg} \mathrm{kg}^{-1}\right)$, em delineamento inteiramente ao acaso, com cinco tratamentos e cinco repetições. Não foi observado efeito significativo da suplementação com vitamina E sobre o comprimento total, volume corpuscular médio, concentração de hemoglobina corpuscular média e número de eritrócitos, nem sobre a atividade da glutationa peroxidase. Peso final e conversão alimentar aparente, no entanto, sofreram efeito dos tratamentos suplementados. O teor de $400 \mathrm{mg} \mathrm{kg}^{-1}$ de vitamina $\mathrm{E}$ melhorou o comprimento padrão e ganho de peso. A suplementação da dieta com vitamina $\mathrm{E}$ resulta em melhor desempenho produtivo de tambacus.

Termos para indexação: Colossoma macropomum, Piaractus mesopotamicus, enzimologia, hematologia, tocoferol.

\section{Productive performance of tambacus fed diets supplemented with vitamin $E$}

\begin{abstract}
The objective of this work was to evaluate the effects of tambacu vitamin E dietary supplementation on performance and hematological variables, and determine the relationship of glutathione peroxidase activity with vitamin $\mathrm{E}$ and selenium suplementation. Two hundred and fifty juvenile tambacus were used, divided into 25 aquaria. The basal diet was pelleted with $32 \%$ of crude protein and $3,300 \mathrm{kcal} \mathrm{kg}^{-1}$ of digestible energy, with $0.40 \mathrm{mg} \mathrm{kg}^{-1} \mathrm{Se}$. Test diets - isoproteic and isocaloric - were composed of the basal diet with increasing vitamin E concentrations $\left(0,100,200,300,400 \mathrm{mg} \mathrm{kg}^{-1}\right)$, in a completely randomized design, with five treatments and five replications. No significant effect of vitamin E supplementation was observed on total length, mean corpuscular volume, mean corpuscular hemoglobin concentration and total erythrocyte, and on the enzymatic activity of glutathione peroxidase. However, final weight and apparent feed conversion were significantly affected by supplemented treatments. Standard length and weight gain improved using diets supplemented with $400 \mathrm{mg} \mathrm{kg}^{-1}$ of vitamin E. Dietary vitamin E supplementation results in better tambacu performance.
\end{abstract}

Index terms: Colossoma macropomum, Piaractus mesopotamicus, enzymology, hematology, tocopherol.

\section{Introdução}

O tambacu é um híbrido resultante do cruzamento induzido entre a fêmea do tambaqui (Colossoma macropomum) e o macho do pacu (Piaractus mesopotamicus). Possui hábito onívoro e suas características de formato, porte e cor acinzentada se assemelham às do tambaqui (Souza, 1998).

O tambaqui é a principal espécie amazônica cultivada no Brasil e pode atingir, na natureza, peso ao redor de 30 quilos. Nessa espécie, a produção de alevinos é fácil e o seu crescimento é rápido. $\mathrm{O}$ tambaqui é cultivado em todo o Brasil, com risco de mortalidade durante os meses de inverno, principalmente nas regiões Sul e Sudeste, onde a água pode atingir temperaturas abaixo de $17^{\circ} \mathrm{C}$ (Souza, 1998). O pacu é um peixe muito comum nas bacias dos rios Paraná, Uruguai e Paraguai, e possui fácil adaptação a sistemas de cultivo intensivo. $\mathrm{O}$ alto valor comercial da carne, a aceitação de alimentação artificial e o rápido crescimento proporcionam larga utilização dessas espécies na piscicultura brasileira

Pesq. agropec. bras., Brasília, v.45, n.9, p.1005-1011, set. 2010 
(Bittencourt, 2008). O tambacu é uma espécie que tolera melhor as baixas temperaturas dos meses de inverno, nas regiões Sul e Sudeste, e apresenta crescimento mais rápido que o pacu (Melo \& Pereira, 1994).

A estocagem, a concentração de vitaminas e minerais, a biodisponibilidade dos nutrientes são exemplos de parâmetros da dieta que interferem no desenvolvimento do animal (Navarro et al., 2007, 2010). Entre os micronutrientes, a vitamina E é o mais importante antioxidante metabólico presente na membrana celular, e a protege da oxidação de ácidos graxos e do colesterol, além de diminuir ou inibir a produção e ação de radicais livres (Noguchi, 1973). De acordo com Tocher et al. (2002) e Guerra et al. (2004), menores quantidades de vitamina $\mathrm{E}$ nas dietas levam à diminuição de sua concentração nos músculos e ao aumento da atividade oxidante do organismo, o que resulta em altas concentrações de peróxidos lipídicos. Assim, em quantidades suficientes, a presença dessa vitamina evita a formação de lipoperóxidos tóxicos e impede a formação de lesões nos vasos sanguíneos e alteração na permeabilidade capilar (Navarro et al., 2009).

Os sinais de deficiência dessa vitamina estão relacionados com a degeneração da membrana, decorrente da peroxidação dos lipídios e derivados, com queda no ganho de peso, degeneração muscular, hemorragia cutânea, escurecimento da pele, ineficiência reprodutiva, degeneração lipídica do fígado e, consequentemente, maior susceptibilidade ao estresse oxidativo e infecções (Izquierdo et al., 2001; Chen et al., 2004). As vitaminas são fornecidas aos peixes em pequenas quantidades para promover crescimento, reprodução e metabolismo normais. A inclusão de vitaminas em alimentos para peixes é necessária em regimes intensivos de produção em que a disponibilidade de alimento natural é restrita.

O selênio está associado a proteínas no tecido animal (Burk \& Hill, 1993). A deterioração oxidativa acarreta perdas nos valores nutricionais e na qualidade da carne. Para aumentar a estabilidade oxidativa da carne, antioxidantes como o Se são adicionados à dieta dos animais de cultivo, o que melhora a qualidade da carne e a torna menos suscetível a danos causados pela oxidação (Downs et al., 2000). O Se é um nutriente essencial, que participa de várias funções fisiológicas como parte integrante de uma série de selenoproteínas (Lin \& Shiau, 2005a; Kohrle et al., 2005). As selenoproteínas compreendem pelo menos 20 proteínas eucarióticas, com expressão individual caracterizada pela alta especificidade com tecidos. A família da glutationa peroxidase (GSH-Px ou GPx) corresponde às selenoproteínas mais bem caracterizadas, e o grau de atividade dessa enzima no fígado ou no plasma é indicado pela presença de selênio no organismo (Lin \& Shiau, 2005a, Kohrle et al., 2005).

A maioria dos estudos sobre peixes concorda que um dos principais sinais de deficiência da vitamina E em parâmetros sanguíneos é a anemia grave, caracterizada pela redução do número eritrocitário, menor percentagem de hematócrito e concentrações de hemoglobina, diminuição do volume corpuscular médio e aumento da proporção de eritrócitos imaturos (Bai \& Lee, 1998; Chen et al., 2004; Puangkaew et al., 2005).

O objetivo deste trabalho foi avaliar os efeitos da suplementação da dieta de tambacu (Colossoma macropomum x Piaractus mesopotamicus) com concentrações de vitamina $\mathrm{E}$ sobre variáveis de desempenho e hematológicas, bem como avaliar os efeitos da suplementação de vitamina $\mathrm{E}$ e inclusão de selênio sobre a atividade enzimática da glutationa peroxidase.

\section{Material e Métodos}

O experimento foi conduzido na estação de piscicultura do Departamento de Zootecnia da Universidade Federal de Lavras (UFLA), de março a maio de 2009, num total de 65 dias.

Foram utilizados 25 aquários de fibra de vidro com 40x61x44 cm de altura e de diâmetro superior e de base, respectivamente, com capacidade total de 100 litros, divididos em duas baterias (sistemas) de aquários.

Foram adquiridos 350 tambacus provenientes da piscicultura Águas Claras, situada em Mococa, SP. Os peixes passaram por um período de 15 dias de adaptação à alimentação e ao ambiente. Desse total, foram selecionados 250 peixes com peso e comprimento médio inicial de $12,12 \pm 0,31 \mathrm{~g}$ e $8,92 \pm 0,73 \mathrm{~cm}$, respectivamente, distribuídos em 25 aquários, com 10 animais cada.

Utilizou-se um sistema de recirculação de água com biofiltro e bomba de $0,5 \mathrm{cv}$, com renovação 
diária de $10 \%$, para limpeza dos aquários por meio de sifonagem. A temperatura foi controlada com uso de termostato e o teor de oxigênio dissolvido foi medido diariamente com oxímetro digital, modelo YSI 55 (YSI Incorporated, Yellow Spring, EUA); o pH e a amônia foram medidos semanalmente por meio de kit colorimétrico comercial (Alcon Labcon, Camboriú, Brasil). Os valores médios de temperatura, $\mathrm{pH}$, oxigênio dissolvido e amônia permaneceram dentro das condições ótimas para o desenvolvimento da espécie (Baldisserotto, 2002; Queiroz \& Silveira, 2006): $27,4 \pm 0,99^{\circ} \mathrm{C}, 7,00 \pm 0,28 \mathrm{mg} \mathrm{L}^{-1}, 7,85 \pm 1,06 \mathrm{mg} \mathrm{L}^{-1} \mathrm{e}$ $0,15 \pm 0,07 \mathrm{mg} \mathrm{L}^{-1}$, respectivamente.

$\mathrm{O}$ arraçoamento foi realizado duas vezes ao dia, às 08 e $16 \mathrm{~h}$. Inicialmente, foi fornecida quantidade de alimento equivalente a $2,5 \%$ do peso vivo, e a dieta foi reajustada semanalmente, de acordo com o desenvolvimento dos animais. O consumo total durante o período experimental foi de $760 \mathrm{~g}$ de ração por aquário. A iluminação foi controlada no regime de 12:12 horas de claro:escuro.

Para dieta basal do tambacu, foi produzida ração peletizada com $32 \%$ de proteína bruta $(\mathrm{PB})$ e 3.300 $\mathrm{kcal} \mathrm{kg}^{-1}$ de energia digestível, de acordo com Nutrient Requirement Council (1993), com inclusão de $0,40 \mathrm{mg} \mathrm{kg}^{-1} \mathrm{de}$ Se na dieta (Tabela 1). Utilizou-se a Selenometionina $(0,5 \%$ ativa) como fonte orgânica de selênio.

As dietas-teste-isoprotéicas e isoenergéticas - foram compostas da dieta basal com concentrações crescentes de vitamina $E\left(0,100,200,300\right.$ e $\left.400 \mathrm{mg} \mathrm{kg}^{-1}\right)$, e o tocoferol acetato ( $50 \%$ ativo) foi utilizado como fonte da vitamina.

As rações foram elaboradas no Laboratório de Nutrição Animal do Departamento de Zootecnia, na UFLA. Os ingredientes foram pesados em balança analítica e homogeneizados com $35 \%$ de água. A mistura final foi processada em moedor de carne sem hélice. Após esses procedimentos, as rações foram secadas em estufa ventilada a $55^{\circ} \mathrm{C}$ e quebradas na forma de péletes.

Ao final do período experimental, os tambacus passaram por 24 horas de jejum. Todos os peixes foram utilizados para coleta de dados. Os dez tambacus de cada aquário foram pesados, em balança digital, e medidos com paquímetros para obtenção dos dados de desempenho: peso final, comprimento total, comprimento padrão, ganho de peso, conversão alimentar aparente.

Em seguida, os peixes foram anestesiados com solução de benzocaína (1 g $\left.15 \mathrm{~L}^{-1}\right)$ e, por punção cardíaca, com auxílio de seringa previamente heparinizada, foram colhidos $1,5 \mathrm{~mL}$ de sangue de cada animal. Dessa alíquota, 1,0 mL, contido em Eppendorff, destinou-se à determinação da contagem de eritrócitos e hemoglobina. A percentagem de hematócrito foi obtida com uso de tubos capilares, com coleta em duplicata. Após a coleta de sangue, os fígados foram retirados, colocados em tubos criogênicos e armazenados em nitrogênio a $-196^{\circ} \mathrm{C}$. Posteriormente, esses materiais foram transferidos do nitrogênio para um freezer a $-80^{\circ} \mathrm{C}$. A análise enzimática (GPx) foi realizada nas amostras de fígado. Para amostragem sanguínea e enzimática, foram utilizados dois peixes por unidade experimental (aquário), num total de 50 peixes.

Para análise enzimática no fígado, foi necessário o processamento do material para obtenção do sobrenadante. Os fígados dos peixes foram retirados do

Tabela 1. Composições percentuais, químicas e calculadas da dieta basal.

\begin{tabular}{lr}
\hline Ingredientes & Quantidade \\
\hline Farelo de soja (\%) & 60,00 \\
Farelo de trigo (\%) & 21,16 \\
Milho (\%) & 9,80 \\
Óleo de soja (\%) & 6,75 \\
Fosfato bicálcico (\%) & 0,10 \\
Calcário (\%) & 0,62 \\
Sal (\%) & 0,40 \\
Premix vitamínico e mineral (\%) ${ }^{(1)}$ & 0,60 \\
Metionina (\%) & 0,55 \\
BHT (\%) & 0,02 \\
Selênio (mg kg-1) & 0,40 \\
\hline Composição da dieta & 31,98 \\
\hline Proteína bruta (\%) & $3.299,02$ \\
Energia Digestível $\left(\mathrm{kcal} \mathrm{kg}^{-1}\right)$ & 8,01 \\
Extrato Etéreo (\%) & 5,71 \\
Fibra bruta (\%) & 0,48 \\
Cálcio (\%) & $(2)$ \\
Fósforo (\%) & 0,59 \\
\hline
\end{tabular}

(1)Premix vitamínico comercial $\left(5 \mathrm{~kg} \mathrm{ton}^{-1}\right)$, com níveis de garantia por quilograma de produto: Vit. A, 1.200.000 UI; Vit. D3, 200.000 UI; Vit K3, $2.400 \mathrm{mg}$; Vit B3. $4.800 \mathrm{mg}$; Vit B2, $4.800 \mathrm{mg}$; Vit B6, $4.000 \mathrm{mg}$; Vit B12, $4.800 \mathrm{mg}$; ácido fólico, $1.200 \mathrm{mg}$; pantotenato Ca $12.000 \mathrm{mg}$; Vit. C, $48.000 \mathrm{mg}$; biotina, $48 \mathrm{mg}$; cloreto de colina, $108.000 \mathrm{mg}$; niacina, 24.000 mg e premix mineral comercial $\left(1 \mathrm{~kg}\right.$ ton $\left.^{-1}\right)$, com níveis de garantia por quilograma do produto: $\mathrm{Fe}, 50.000 \mathrm{mg}$; $\mathrm{Cu}, 3.000 \mathrm{mg} ; 20.000 \mathrm{mg}$; $\mathrm{Mn}$, 20.000 mg; Zn, 3.000 mg; I, 100 mg; Co, 10 mg; Se, 100 mg. ${ }^{(2)}$ Com base em valores calculados para a dieta. 
freezer e lavados em solução salina a $0,9 \%$ para remover o excesso de sangue. O material foi seco em papel-filtro e pesado $0,5 \mathrm{~g}$ de cada amostra. Cada amostra de fígado foi colocada em um Eppendorff, e posteriormente foi diluída (10x) em solução tampão de fosfato, a $20 \mathrm{mmol} \mathrm{L}^{-1} \mathrm{pH} 7,4$, com $0,1 \%$ de Triton e $150 \mathrm{mmol} \mathrm{L}^{-1}$ de $\mathrm{NaCl}$. A homogeneização foi realizada em agitador de tubos tipo vortex, modelo QL-901 (Meditry Medical Development Co. Ltd. Shanghai, China), mantido em gelo picado, por dez impactos seguidos de centrifugação refrigerada a $14.515 \mathrm{~g}$, por três minutos. Os sobrenadantes foram transferidos para novos Eppendorff's e mantidos a $-20^{\circ} \mathrm{C}$ até análise.

A metodologia enzimática está de acordo com Flohé \& Günzler (1984), em que a GPx dismuta o t-BuOOH do ensaio e produz uma ponte dissulfeto entre duas GSH (GS-GS), que por sua vez volta ao estado reduzido (2 GSH), pela ação da glutationa redutase (GR). A GR age mediante a oxidação de NADPH. Este ensaio baseia-se na medida do decréscimo de absorbância $(340 \mathrm{~nm})$ que ocorre durante a redução da GSSG, catalisada pela GR, em presença de NADPH. A velocidade de oxidação do NADPH é proporcional à velocidade de produção de GSSG a partir da GSH em presença de t-BuOOH, catalisada pela GPx. Os valores da atividade desta enzima são expressos em $\mu \mathrm{mol} \mathrm{min}^{-1} \mathrm{~g}^{-1}$ para tecidos e $\mu \mathrm{mol} \mathrm{min} \mathrm{mL}^{-1} \mathrm{~mL}^{-1}$ para lisados ou extratos.

A concentração da glutationa peroxidase foi determinada pelo método ELISA, com uso de um kit de atividade de GPx STRESSGEN (Assay Designs, Ann Arbor, EUA). A leitura foi realizada por leitor automático de microplacas modelo Power Wave XS com 96 poços (Biotek, Winooski, EUA), por meio do programa GEN 5. O tempo de leitura foi de 2,5 minutos, e as análises foram realizadas a cada 30 segundos. Durante cada intervalo de leitura, as placas foram agitadas por dez segundos. As análises de GPx foram realizadas no material em triplicata. A atividade da enzima foi dada pela equação: atividade $=\left(\Delta \mathrm{A}_{340} \min 0,00379 \mu \mathrm{M}^{-1}\right) \times\left(0,2 \mathrm{~mL} \mathrm{YmL}^{-1}\right)$ $\mathrm{x}$ diluição $\left(\mathrm{nmolmin}^{-1} \mathrm{~mL}^{-1}\right)$, em que $\mathrm{Y}$ é a alíquota de amostra. A atividade é expressa por $\mathrm{g}$ de proteína. Para converter a $\mu \mathrm{mol} \mathrm{min}^{-1} \mathrm{~g}^{-1}$, utilizou-se a fórmula: atividade $=\left(\right.$ valor em nmol min $\left.\mathrm{mL}^{-1} \times 9\right) / 1.000$.

A análise de hemoglobina foi realizada por meio de absorbância, em espectrofotômetro Cary 50 UV-Visible (Varian Inc., Santa Clara, EUA), a $540 \mathrm{~nm}$, com 0,2 $\mathrm{mL}$ de sangue em $5 \mathrm{~mL}$ de $\mathrm{KCN}$, de acordo com metodologia descrita por Evelyn \& Malloy (1938).

Para determinação do percentual de hematócrito, utilizou-se a metodologia do micro-hematócrio, segundo Goldenfarb et al. (1971). A contagem total de eritrócitos foi realizada em câmara de Neubauer, após diluição de $20 \mu \mathrm{L}$ de sangue em $4 \mathrm{~mL}$ de solução cloreto de sódio a $0,65 \%$, de acordo com a metodologia de Natt \& Herrick (1952). Os valores de eritrócitos foram calculados por meio da contagem de cinco quadrados médios (Neubauer), multiplicados por 10.050.

Com os resultados da taxa de hemoglobina $(\mathrm{Hb})$, hematócrito $(\mathrm{Ht})$ e número de eritrócitos $(\mathrm{Er})$, foram calculados os índices hematimétricos absolutos: volume corpuscular médio (VCM) e concentração de hemoglobina corpuscular média (CHCM), em que $\mathrm{VCM}(\mathrm{fL})=(\mathrm{Ht} \times 10) / \mathrm{Er}$ e CHCM $\left(\mathrm{g} \mathrm{dL}^{-1}\right)=(\mathrm{Hb} \times$ 100)/Ht.

Os tratamentos foram as concentrações de suplementação com vitamina $\mathrm{E}(0,100,200,300$ e $400 \mathrm{mg} \mathrm{kg}^{-1}$ ), distribuidos em delineamento experimental inteiramente ao acaso, com cinco repetições. Os resultados obtidos foram submetidos à análise de variância, por meio do pacote computacional Sistema para Análise de Variância (Sisvar), descrito por Ferreira (2000). As médias calculadas foram

Tabela 2. Médias das variáveis de desempenho de juvenis de tambacu, de acordo com os níveis de suplementação com vitamina E na dieta ${ }^{(1)}$.

\begin{tabular}{|c|c|c|c|c|c|c|}
\hline \multirow[t]{2}{*}{ Variável } & \multicolumn{5}{|c|}{ Vitamina E $\left(\mathrm{mg} \mathrm{kg}^{-1}\right)^{(1)}$} & \multirow[t]{2}{*}{$\mathrm{CV}(\%)$} \\
\hline & 0 & 100 & 200 & 300 & 400 & \\
\hline Peso final (g) & $68,80 \mathrm{~b}$ & $79,80 \mathrm{a}$ & $79,20 \mathrm{a}$ & $77,40 \mathrm{a}$ & $82,40 a$ & 7,94 \\
\hline Comprimento total $(\mathrm{cm})$ & $15,68 \mathrm{a}$ & $16,20 \mathrm{a}$ & $16,02 \mathrm{a}$ & $16,00 \mathrm{a}$ & $16,50 \mathrm{a}$ & 3,41 \\
\hline Comprimento padrão $(\mathrm{cm})$ & $11,98 \mathrm{~b}$ & $12,84 \mathrm{ab}$ & $12,90 \mathrm{ab}$ & $12,80 \mathrm{ab}$ & $13,20 \mathrm{a}$ & 4,24 \\
\hline Ganho de peso $(\mathrm{g})$ & $56,80 \mathrm{~b}$ & $67,67 \mathrm{ab}$ & $67,10 \mathrm{ab}$ & $65,34 \mathrm{ab}$ & $70,27 \mathrm{a}$ & 9,53 \\
\hline Conversão alimentar (g) & $1,34 b$ & $1,13 \mathrm{a}$ & $1,15 \mathrm{a}$ & $1,17 \mathrm{a}$ & $1,09 \mathrm{a}$ & 9,57 \\
\hline
\end{tabular}

${ }^{(1)}$ Médias seguidas por letras iguais nas linhas não diferem entre si pelo teste SNK, a 5\% de probabilidade. 
submetidas ao teste de Student-Newman-Keuls, a 5\% de probabilidade.

\section{Resultados e Discussão}

Não foi observado efeito significativo da suplementação com vitamina E no comprimento total do tambacu (Tabela 2). No entanto, o peso final e comprimento padrão apresentaram diferenças significativas. Isso ocorre porque, no início do crescimento da fase juvenil, o tambacu necessita desenvolver melhor seu corpo para alojar os órgãos vitais, e isso reflete-se mais fortemente no peso do que no comprimento total. Quanto ao peso final, os peixes tratados com suplementação da vitamina E alcançaram melhores respostas que os peixes que não receberam suplementação, o que demonstra a eficiência da vitamina na alimentação dos tambacus. Paul et al. (2004) obtiveram resultados semelhantes, com melhora no peso final de carpa mrigal (Cirrhinus mrigala) com utilização de $120 \mathrm{mg} \mathrm{kg}^{-1}$ de vitamina $\mathrm{E}$.

$\mathrm{O}$ maior comprimento padrão dos peixes foi obtido com a maior concentração de vitamina (400 $\mathrm{mg} \mathrm{E} \mathrm{kg}^{-1}$ de ração), que no entanto diferiu significativamente apenas do tratamento sem suplementação. Huang et al. (2004), em estudos realizados com salmões (Oncorhynchus kisutsh), relataram taxas de crescimento semelhantes entre os peixes alimentados com $100 \mathrm{mg} \mathrm{kg}^{-1}$ de vitamina $\mathrm{E}$ e o grupo controle. Já Ruff (2002) não observou diferença de crescimento entre os tratamentos com 189 e $613 \mathrm{mg} \mathrm{kg}^{-1}$ de vitamina E para alabote-do-atlântico (Hippoglossus hippoglossus).

Os maiores ganhos de peso também foram observados com a maior concentração de vitamina na dieta, com diferença significativa para o tratamento controle (Tabela 2). Esses resultados foram semelhantes aos de Paul et al. (2004), que observaram melhoria no ganho de peso em carpa mrigal quando utilizaram $120 \mathrm{mg} \mathrm{kg}^{-1}$ de vitamina E. Lin \& Shiau (2005b) avaliaram o desempenho de garoupas (Epinephelus malabaricus) alimentadas durante oito semanas com sete dietas suplementadas com vitamina $\mathrm{E}$ ( 0 a $800 \mathrm{mg} \mathrm{kg}^{-1}$ de dieta), e observaram que o ganho de peso foi maior em peixes alimentados com mais de $100 \mathrm{mg} \mathrm{kg}^{-1}$.

Quanto à conversão alimentar aparente, a concentração de $100 \mathrm{mg} \mathrm{kg}^{-1}$ de vitamina E melhorou o desempenho alimentar, em razão do maior aproveitamento da dieta nesse tratamento. Esses resultados são contrários aos de Kiron et al. (2004), que não observaram diferenças no ganho de peso e conversão alimentar aparente para trutas-arco-íris (Oncorhynchus mykiss) alimentadas com rações com 100 e $1.000 \mathrm{mg} \mathrm{kg}^{-1}$ de vitamina $\mathrm{E}$.

A suplementação de vitamina E na dieta não apresentou efeito significativo sobre a atividade da glutationa peroxidase (GPx), com variação de 18,74 a 23,53 $\mu$ mol $\min ^{-1} \mathrm{~g}^{-1}(\mathrm{CV}=33,69 \%)$. Este fato pode ser explicado pela relação indireta da glutationa peroxidase com o tocoferol, que, apesar de possuírem o mesmo papel antioxidante, agem em diferentes locais da célula: a GPx age no citosol, e apresenta selênio em sua composição (Halliwell \& Gutteridge, 2007), enquanto tocoferol age nas membranas celulares (Evans, 2000). O mesmo foi observado por Trenzado et al. (2009), que utilizaram duas concentrações de vitamina E, 25,6 e 275,6 mg kg $\mathrm{mg}^{-1}$, e duas de ácido graxos altamente insaturados (HUFA), 12,5 e $30,5 \mathrm{~g} \mathrm{~kg}^{-1}$, e não observaram efeito significativo da suplementação com vitamina E sobre a ação da enzima glutationa peroxidase (GPx). Tocher et al. (2002) trabalharam com 0,100 e $1.000 \mathrm{mg} \mathrm{kg}^{-1}$ de vitamina $\mathrm{E}$, e relataram que alabotes (Hippoglossus hippoglossus) alimentados com alta dosagem de vitamina na dieta apresentaram menor atividade da GPx (25 nmol min $\left.{ }^{-1} \mathrm{mg}^{-1}\right)$. Em dourada (Sparus aurata), a atividade da enzima glutationa peroxidase não foi alterada pela suplementação da dieta com vitamina $\mathrm{E}$ (média de $168 \mathrm{nmol} \mathrm{min}{ }^{-1} \mathrm{mg}^{-1}$ ), o que mostra que respostas de atividade da GPx à suplementação

Tabela 3. Características hematológicas de tambacus alimentados com dietas suplementadas com diferentes concentrações de vitamina $\mathrm{E}^{(1)}$.

\begin{tabular}{|c|c|c|c|c|c|c|}
\hline \multirow[t]{2}{*}{ Variável } & \multicolumn{5}{|c|}{ Vitamina $\mathrm{E}\left(\mathrm{mg} \mathrm{kg}^{-1}\right)$} & \multirow[t]{2}{*}{$\mathrm{CV}(\%)$} \\
\hline & 0 & 100 & 200 & 300 & 400 & \\
\hline Eritrócitos $\left(10^{6} \mu \mathrm{L}^{-1}\right)$ & $3,68 \mathrm{a}$ & $3,72 \mathrm{a}$ & $3,42 \mathrm{a}$ & $3,96 \mathrm{a}$ & $3,58 \mathrm{a}$ & 27,69 \\
\hline VCM (fL) & $131,16 a$ & $156,50 \mathrm{a}$ & $123,38 \mathrm{a}$ & $123,54 \mathrm{a}$ & $139,00 \mathrm{a}$ & 35,07 \\
\hline $\mathrm{CHCM}\left(\mathrm{g} \mathrm{dL}^{-1}\right)$ & $24,26 a$ & $22,90 \mathrm{a}$ & $22,42 \mathrm{a}$ & $24,08 \mathrm{a}$ & $20,54 a$ & 15,35 \\
\hline
\end{tabular}

${ }^{(1)}$ Médias seguidas por letras iguais nas linhas não diferem entre si pelo teste SNK, a 5\% de probabilidade. VCM, volume corpuscular médio, em fentolitro (fL, $10^{-15} \mathrm{~L}$; CHCM, concentração de hemoglobina corpuscular média. 
da vitamina E podem variar de acordo com a espécie em estudo.

Não foi observado efeito significativo da suplementação com vitamina $\mathrm{E}$ nas variáveis sanguíneas (Tabela 3). É possível que os peixes tenham apresentado equilíbrio fisiológico, pois o ambiente apresentava temperatura ideal, alta concentração de oxigênio, densidade populacional adequada, assimilação de nutrientes adequada, e, por isso, não evidenciaram alterações nos padrões sanguíneos, o que também foi observado por Tavares-Dias \& Moraes (2004) em diversas espécies de teleósteos. Garcia et al. (2007), ao utilizar suplementação com vitamina E na dieta de pacus (Piaractus mesopotamicus), não observaram efeito sobre o total de eritrócitos e contagem total de proteína e globulinas no sangue dos peixes. A suplementação também não acarretou diferenças significativas em VCM e CHCM. Entretanto, Trenzado et al. (2009), ao avaliar o efeito de concentrações de vitamina E (25,6 e 275,6 mg kg-1) e de HUFA (12,5 e $30,5 \mathrm{~g} \mathrm{~kg}^{-1}$ ) em truta-arco-íris, observaram que peixes com dietas deficientes em vitamina $\mathrm{E}$ apresentaram maiores valores de CHCM e menores valores de VCM. Esses autores também observaram que a ausência da vitamina $\mathrm{E}$ e altas concentrações de HUFA levam os peixes ao estágio de anemia.

Chen et al. (2004) constataram que a deficiência de vitamina $\mathrm{E}$ promove sinais clínicos distintos em juvenis de "golden shiner" (Notemigonus crysoleucas) alimentados por 10 semanas com dieta desprovida da vitamina. Entre os sinais observados, estão o escurecimento da superfície corporal, resposta lenta à alimentação, natação errática, caquexia associada com a perda do músculo epaxial e hemorragia. Cortes histológicos da musculatura revelaram que algumas fibras estavam severamente atrofiadas, necrosadas e com infiltrados inflamatórios de leucócitos nos tecidos conectivos.

\section{Conclusões}

1. A suplementação das dietas com vitamina $E$ influencia positivamente o peso final, o comprimento padrão, o ganho de peso e a conversão alimentar aparente de juvenis de tambacu, com maior aproveitamento da dieta e melhor rendimento produtivo dos peixes.

2. A atividade da enzima glutationa peroxidase está diretamente ligada à quantidade de selênio disponível na dieta e não à suplementação por vitamina $\mathrm{E}$.
3. As variáveis sanguíneas de animais em equilíbrio fisiológico não são afetadas pela suplementação com vitamina $\mathrm{E}$, nas condições avaliadas.

\section{Referências}

BAI, S.C.; LEE, K.J. Different levels of dietary DL-a-tocopheryl acetate affect the vitamin E status of juvenile Korean rockfish, Sebastes schlegeli. Aquaculture, v.161, p.405-418, 1998.

BALDISSEROTTO, B. Fisiologia de peixes aplicada à piscicultura. Santa Maria: UFSM, 2002. 212p.

BITTENCOURT, F. Cultivo de pacu Piaractus mesopotamicus sob diferentes densidades em tanque-rede no reservatório de Itaipu. 2008. 46p. Dissertação (Mestrado) - Universidade Estadual do Oeste do Paraná, Marechal Cândido Rondon.

BURK, R.F.; HILL, K.E. Regulation of selenoproteins. Annual Review of Nutrition, v.13, p.65-81, 1993.

CHEN, R.G.; LOCHMANN, R.; GOODWIN, A.; PRAVEEN, K.; DABROWSKI, K.; LEE, K.-J. Effects of dietary vitamins $\mathrm{C}$ and $\mathrm{E}$ on alternative complement activity, hematology, tissue composition, vitamin concentrations and response to heat stress in juvenile golden shiner (Notemigonus crysoleucas). Aquaculture, v.242, p.553-569, 2004.

DOWNS, K.M.; HESS, J.B.; BILGILI, S.F. Selenium source effect on broiler carcass characteristics, meat quality and drip loss. Journal of Applied Animal Research, v.18, p.61-72, 2000.

EVANS, W.J.Vitamin E, vitamin C, and exercise. American Journal of Clinical Nutrition, v.72, p.647-652, 2000. Supplement.

EVELYN, K.A.; MALLOY, H.T. Microdetermination of oxyhemoglobin, methemoglobin and sulfhemoglobin in a single sample of blood. The Journal of Biological Chemistry, v.126, p.655-662, 1938.

FERREIRA, D.F. Sistema SISVAR para análises estatísticas: manual de orientação. Lavras: UFLA, 2000. 37p.

FLOHÉ, L.; GÜNZLER, W.A. Assays of glutathione peroxidase. Methods in Enzymology, v.105, p.114-121, 1984.

GARCIA, F.; PILARSKI, F.; ONAKA, E.M.; MORAES, F.R. de; MARTINS, M.L. Hematology of Piaractus mesopotamicus fed diets supplemented with vitamins $\mathrm{C}$ and $\mathrm{E}$, challenged by Aeromonas hydrophila. Aquaculture, v.271, p.39-46, 2007.

GOLDENFARB, P.B.; BOWYER, F.P.; HALL, E.; BROSIOUS, E. Reproducibility in the hematology laboratory: the microhematocrit determination. American Journal of Clinical Pathology, v.56, p.35-39, 1971.

GUERRA, M.M.P.; EVANS, G.; MAXWELL, W.M.C. Papel de oxidantes e anti-oxidantes na andrologia: revisão de literatura. Revista Brasileira de Reprodução Animal, v.28, p.187-195, 2004.

HALLIWELL, B.; GUTTERIDGE, J.M.C. Free radicals in biology and medicine. New York: Oxford University, 2007. $851 \mathrm{p}$.

HUANG, C.-H.; HIGGS, D.A.; BALFRY, S.K.; DEVLIN, R.H. Effect of dietary vitamin E level on growth, tissue lipid 
peroxidation, and erythrocyte fragility of transgenic coho salmon, Oncorhynchus kisutch. Comparative Biochemistry and Physiology - Part A: Molecular and Integrative Physiology, v.139, p.199-204, 2004.

IZQUIERDO, M.S.; FERNÁNDEZ-PALACIOS, H.; TACON, A.G.J. Effect of broodstock nutrition on reproductive performance of fish. Aquaculture, v.197, p.25-42, 2001.

KIRON, V.; PUANGKAEW, J.; ISHIZAKA, K.; SATOH, S.; WATANABE, T. Antioxidant status and nonspecific immune responses in rainbow trout (Oncorhynchus mykiss) fed two levels of vitamin E along with three lipid sources. Aquaculture, v.234, p.361-379, 2004.

KOHRLE, J.; JAKOB, F.; CONTEMPRE, B.; DUMONT, J. Selenium, the thyroid, and the endocrine system. Endocrine Reviews, v.26, p.944-984, 2005.

LIN, Y.-H.; SHIAU, S.-Y. Dietary selenium requirements of juvenile grouper, Epinephelus malabaricus. Aquaculture, v.250, p.356-363, 2005a.

LIN, Y.-H.; SHIAU, S.-Y. Dietary vitamin E requirement of grouper, Epinephelus malabaricus, at two lipid levels, and their effects on immune responses. Aquaculture, v.248, p.235-244, 2005b.

MELO, J.S.C.; PEREIRA, J.A. Crescimento do híbrido tambacu (fêmea de Colossoma macropomum x macho de Piaractus mesopotamicus) em criação intensiva. Boletim Técnico do CEPTA, v.7, p.59-75, 1994.

NATT, M.P.; HERRICK, C.A. A new blood diluent for counting the erythrocytes and leucocytes of the chicken. Poultry Science, v.31, p.735-738, 1952.

NAVARRO, R.D.; LANNA, E.A.T.; DONZELE, J.L.; MATTA, S.L.P. da; SOUZA, M.A. de. Níveis de energia digestível da dieta sobre o desempenho de piauçu (Leporinus Macrocephalus) em fase pós-larval. Acta Scientiaruam. Animal Sciences, v.29, p.109-114, 2007.

NAVARRO, R.D.; FERREIRA, W.M.; RIBEIRO FILHO, O.P.; VELOSO, D.P.; FONTES, D.O; SILVA, R.F. Desempenho de tilápia do Nilo (Oreochromis Niloticus) suplementada com vitamina E. Archivos de Zootecnia, v.59, p.185-194, 2010.

NAVARRO, R.D.; RIBEIRO FILHO, O.P.; FERREIRA, W.M.; PEREIRA, F.K.S. A importância das vitaminas E, C e A na reprodução de peixes: revisão de literatura. Revista Brasileira de Reprodução Animal, v.33, p.20-25, 2009.

NOGUCHI, T.; CANTOR, A.H.; SCOTT, M.L. Mode of action of selenium and vitamin $\mathrm{E}$ in prevention of exudative diathesis in chicks. The Journal of Nutrition, v.103, p.1502-1511, 1973.

NUTRIENT REQUIREMENTCOUNCIL. Nutrient requirements of fish. Washington: National Academy, 1993. 114p.

PAUL, B.N.; SARKAR, S.; MOHANTY, S.N. Dietary vitamin E requirement of mrigal, Cirrhinus mrigala fry. Aquaculture, v.242, p.529-536, 2004.

PUANGKAEW, J.; KIRON, V.; SATOH, S.; WATANABE, T. Antioxidant defense of rainbow trout (Oncorhynchus mykiss) in relation to dietary n-3 highly unsaturated fatty acids and vitamin E contents. Comparative Biochemistry and Physiology. C. Toxicology and Pharmacology, v.140, p.187-196, 2005.

QUEIROZ, J.F. de; SILVEIRA, M.P. Recomendações práticas para melhorar a qualidade da água e dos efluentes dos viveiros de aquicultura. Jaguariúna: Embrapa Meio Ambiente, 2006. 14p. (Embrapa Meio Ambiente. Circular técnica, 12).

RUFF, N.; GERALD, R.D.; CROSS, T.F.; KERRY, J.P. Fillet shelf-life of Atlantic halibut Hippoglossus hippoglossus L. fed elevated levels of $\alpha$-tocopheryl acetate. Aquaculture Research, v.33, p.1059-1071, 2002.

SOUZA, V.L. Efeitos da restrição alimentar e da realimentação no crescimento e metabolismo energético de juvenis de pacu (Piaractus mesopotamicus Holmberg, 1887). 1998. 118p. Tese (Doutorado) - Universidade Estadual Paulista, Jaboticabal.

TAVARES-DIAS, M.; MORAES, F.R. de. Hematologia de peixes teleósteos. Ribeirão Preto: Villim, 2004. 144p.

TOCHER, D.R.; MOURENTE, G.; VAN DER EECKEN, A.; EVJEMO, J.O.; DIAZ, E.; BELL, J.G.; GEURDEN, I.; LAVENS, P.; OLSEN, Y. Effects of dietary vitamin E on antioxidant defense mechanisms of juvenile turbot (Scophthalmus maximus L.), halibut (Hippoglossus hippoglossus L.) and sea bream (Sparus aurata L.). Aquaculture Nutrition, v.8, p.195-207, 2002.

TRENZADO, C.E.; MORALES, A.E.; PALMA, J.M.; HIGUERA, M. Blood antioxidant defenses and hematological adjustments in crowded/uncrowded rainbow trout (Oncorhynchus mykiss) fed on diets with different levels of antioxidant vitamins and HUFA. Comparative Biochemistry and Physiology. C. Toxicology and Pharmacology, v.149, p.440-447, 2009.

Recebido em 9 de fevereiro de 2010 e aprovado em 2 de agosto de 2010 